\title{
Ocena stopnia uszkodzenia stopu Inconel 718 z zastosowaniem prądów wirowych
}

\author{
Evaluation of damage degree of Inconel 718 \\ with the use of eddy currents
}

\section{Streszczenie}

Zaprezentowane wyniki wskazują na możliwość ilościowej oceny stopnia uszkodzenia, opisanego miarą skumulowanego odkształcenia plastycznego, uzyskanego w statycznej próbie rozciągania, z wykorzystaniem prądów wirowych. Badaniom poddano próbkę o zmiennym polu przekroju w całym zakresie części pomiarowej. Użycie próbki o takiej geometrii umożliwia uzyskanie pola deformacji, której wartość zmienia się wzdłuż osi próbki. Znajomość wartości odkształcenia trwałego w danym przekroju próbki w połączeniu z analizą struktury w tym miejscu pozwala na prześledzenie ewolucji uszkodzenia struktury materiału wywołanej jego deformacją trwałą. Na takiej próbce, poddanej próbie rozciągania, wykonano profil zmian kąta fazowego sygnału prądowirowego w kolejnych obszarach o zmiennym stopniu uszkodzenia. Dokonując korelacji pomiędzy stopniem uszkodzenia wyrażonym miarą parametru uszkodzenia oraz wartością mierzonego kąta fazowego, determinowaną lokalnymi zmianami przewodności elektrycznej i przenikalności magnetycznej uzyskano zależność wskazującą na możliwość nieniszczącej oceny stopnia degradacji materiału poddanego obciążeniom przekraczającym wartość granicy plastyczności.

Słowa kluczowe: ocena uszkodzenia, lokalne pomiary odkształcenia, prądy wirowe

\section{Abstract}

Presented results indicate the possibility of a quantitative evaluation of the damage, described by measure of plastic deformation, obtained in the static tensile test using eddy currents. Samples with variable crosssectional area throughout the range of the measuring section have been tested. Such geometry of the sample allows to obtain the area of deformation which varies along the axis of the sample. Knowledge of the permanent deformation in the given cross-section of the sample in combination with the analysis of the structure at this point allows to investigate the structure of the material damage caused by permanent deformation. On a sample subjected to a tensile test the profile changes of the phase angle of the eddy current signal were performed. Correlation between the degree of damage, expressed by measure of deformation, and the value of the measured phase angle, determined by local changes in electrical conductivity and magnetic permeability was conducted. On the basis of it, the dependence indicating the ability to nondestructive evaluation of the degradation degree of the material, subjected to loads exceeding the yield limit was obtained.

Keywords: evaluation of damage, local measurements of deformation, eddy currents

\section{Wstęp}

Metody ilościowej oceny degradacji materiałów bazują na założeniu korelacji stopnia uszkodzenia z pewną mierzalną wielkością fizyczną. Takie wskaźniki uszkodzenia materiału oparte są na identyfikacji zmian właściwości i/lub mikrostruktury zachodzących $\mathrm{w}$ materiale. W badaniach doświadczalnych procesu uszkodzenia materiału stosowane są metody badań materiałowych, zarówno niszczące (np. metalografia, badania wytrzymałościowe) jak i nieniszczące. Istotną zaletą metod nieniszczących jest to, iż nie wymagają pobierania próbek materiałowych z obiektu badań celem określenia stopnia uszkodzenia materiału.

Badania metodą prądów wirowych znalazły szerokie zastosowanie w defektoskopii, czyli w tej gałęzi badań nieniszczących, których celem jest wykrycie i ilościowa ocena wad materiałowych, technologicznych i eksploatacyjnych mających charakter nieciągłości. Znajdują również coraz szersze zastosowanie do oceny zmian właściwości fizycznych materiałów, takich jak przenikalność magnetyczna czy przewodność elektryczna pod wpływem oddziaływania

Mgr Józef Krysztofik - Instytut Lotnictwa; dr inż. Dominik Kukla - Podstawowych Problemów Techniki; dr hab. inż. Grzegorz Socha, prof nadzw. IS - Instytut Lotnictwa. 
warunków eksploatacyjnych. W ostatnich latach rozwinęły się badania mające na celu określenie korelacji zmian tych właściwości z innymi parametrami uzyskanymi w badaniach niszczących. Degradacja mikrostruktury materiału związana z lokalnym rozwojem odkształcania plastycznego w próbce prowadzi do zmian wartości kąta fazowego impedancji zespolonej prądów wirowych w materiale.

Warunkiem zastosowania metody prądów wirowych jest przewodnictwo elektryczne badanych materiałów, dlatego badania przeprowadzono na stopie niklu Inconel 718. Stop ten jest często wykorzystywany do budowy elementów maszyn i konstrukcji pracujących w ekstremalnych warunkach obciążenia mechanicznego i temperatury. Warto zatem opracować metodyki diagnostyczne do monitorowania rozwoju uszkodzenia i kontroli eksploatacji dla poprawy ich bezpieczeństwa.

\section{Próbki do badań i ich metodyka}

Badaniom poddano partię próbek ze stopu Inconel 718. Degradację materiału wywołano poprzez statyczną próbę rozciągania. Do badań zastosowano próbki z częścią pomiarową o zmiennym polu przekroju (rys. 1.). Użycie próbki o takiej geometrii umożliwia uzyskanie pola deformacji, której wartość zmienia się wzdłuż osi próbki. Znajomość wartości odkształcenia trwałego $\mathrm{w}$ danym przekroju próbki $\mathrm{w}$ połączeniu $\mathrm{z}$ analizą mikrostruktury $\mathrm{w}$ tym miejscu pozwala na prześledzenie ewolucji uszkodzenia struktury materiału wywołanej jego deformacją trwałą. Dzięki temu w badaniach można serię próbek zastąpić jedną próbką, w której występują różne stany degradacji odpowiadające określonym lokalnym odkształceniom. Sposób badania i próbka zostały oznaczone w Urzędzie Patentowym RP.
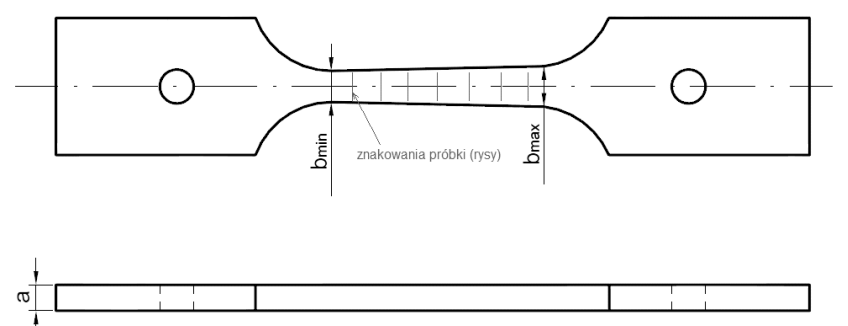

Rys. 1. Próbki do badań degradacji stopu Inconel 718

Fig. 1. Samples used to degradation of the Inconel 718

W oznakowanych przekrojach próbek, dokonano pomiarów odkształceń trwałych dla próbki po statycznych próbach rozciągania w kierunku szerokości i grubości próbki. Następnie z warunku nieściśliwości materiału obliczono wartość odkształcenia w kierunku osi próbki. Na podstawie obliczonej wartości odkształceń obliczono w oparciu o model Johnsona z 1980 roku wartości parametru uszkodzenia D zgodnie z podaną w jego pracy zależnością:

$$
D=\sum \frac{\Delta \varepsilon}{\varepsilon_{f}}
$$

gdzie $\Delta \varepsilon$ jest odkształceniem trwałym w kierunku osi próbki a $\varepsilon_{f}$ jest finalną wartością tego parametru, odpowiadającą zerwaniu próbki.

Na rysunku 2 pokazano zmiany parametru uszkodzenia obliczonego według ww. zależności, w funkcji odległości od przełomu, na próbkach poddanych statycznej próbie rozciągania oraz próbie pełzania. Wykres ten obrazuje stopień uszkodzenia materiału próbki w funkcji odległości od miejsca jej uszkodzenia w najmniejszym przekroju.

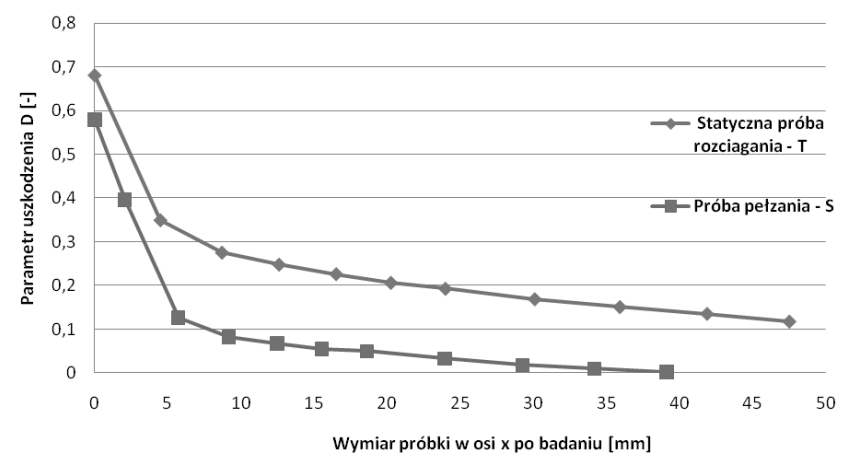

Rys. 2. Parametr uszkodzenia w funkcji odległości od przełomu dla próbki po statycznej próbie rozciągania - T; i próbki po badaniach pełzania - $\mathrm{S}$

Fig. 2. Damage parameter as a function of the distance of the fracture surface for a sample after static tensile test $-\mathrm{T}$ and sample after creep testing $-\mathrm{S}$

Jak widać na obu wykresach parametr uszkodzenia, wyrażony miarą lokalnego odkształcenia, zmienia się w funkcji odległości od przełomu próbki. Pozwala to na ilościową ocenę stanu degradacji dla dowolnego miejsca na próbce. Dzięki temu możliwa będzie korelacja uzyskanych wyników z wynikami pomiarów badań nieniszczących metodą prądów wirowych.

\section{Pomiary kąta fazowego}

impedancji zespolonej prądów wirowych

Kąt fazowy impedancji mierzono z zastosowaniem standardowego defektoskopu prądo-wirowego NORTEC 600 firmy OLYMPUS, którego oprogramowanie umożliwia zautomatyzowany pomiar tego parametru.

Pomiary kąta fazowego $\varphi$ wykonano na próbkach (rys. 3) przed próbą rozciągania w celu oceny jednorodności mierzonego parametru na całej powierzchni próbki. Badania przeprowadzono przy częstotliwości pola elektromagnetycznego cewki 50 oraz $150 \mathrm{kHz}$, co pozwoliło uzyskać penetrację prądów wirowych $\delta \mathrm{w}$ głąb badanego materiału odpowiednio na głębokość 2,53 oraz 1,46 mm. Częstotliwość została dobrana tak, aby głębokość wnikania nie przekraczała grubości próbki w najmniejszym przekroju.

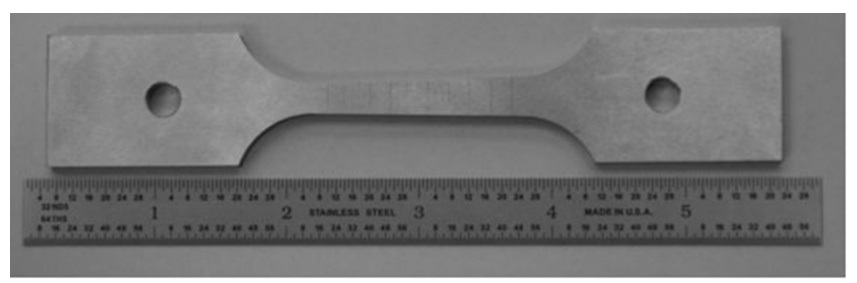

Rys. 3. Próbka wytrzymałościowa ze stopu INCONEL 718 Fig. 3. The sample of strength of the INCONEL 718 alloy

$\mathrm{Na}$ podstawie wstępnych pomiarów stwierdzono, iż na wartość kąta fazowego mierzonego na powierzchni czołowej ma wpływ geometria próbki, a właściwie zmienne pole powierzchni. Jest to związane ze zróżnicowaniem obszaru objętego oddziaływaniem prądów wirowych wzdłuż osi próbki (zmienna szerokość próbki). Związane jest to z tzw. efektem krawędziowym, który zaburza wynik pomiaru. W celu uniknięcia wpływu geometrii pomiary prowadzano również na obu bokach części pomiarowej. W przypadku pomiaru na pow. bocznej efekt krawędziowy, jeżeli nawet wpływa na wynik, to w ten sam sposób na całej długości części pomiarowej i można go pominąć. Rozbieżności wyników pokazano na rysunku 4, gdzie widać wpływ zmiany szerokości próbki przy pomiarze od powierzchni czołowej. 


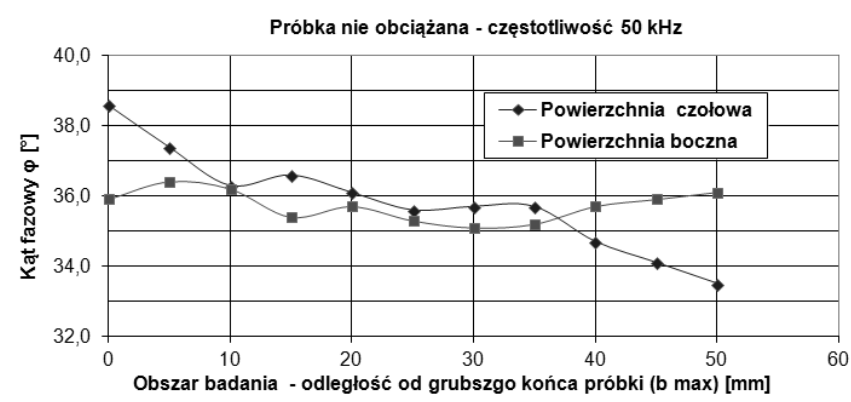

Rys. 4. Zmiany kąta fazowego od sygnału "lift off" uzyskane na powierzchni czołowej oraz bocznej próbki

Fig. 4. Changes in the phase angle of the signal "lift off" obtained on the surface front and side of the sample

Wobec potwierdzenia wpływu zmiany szerokości próbki na lokalną wartość mierzonego parametru kąt fazowy na próbkach uszkodzonych w statycznej próbie rozciągania mierzono na powierzchni bocznej. W ten sposób pominięto wpływ efektu krawędziowego wynikający z wielkości powierzchni na której dokonywany był pomiar.

Kolejne badania dotyczyły złomów próbek po statycznej próbie rozciągania. Pomiar prowadzono od największego przekroju części pomiarowej, aż do miejsca pęknięcia próbki w najmniejszym przekroju. (rys. 5). Pomiar dokonywano poprzez przyłożenie i oddalenie sondy od powierzchni.

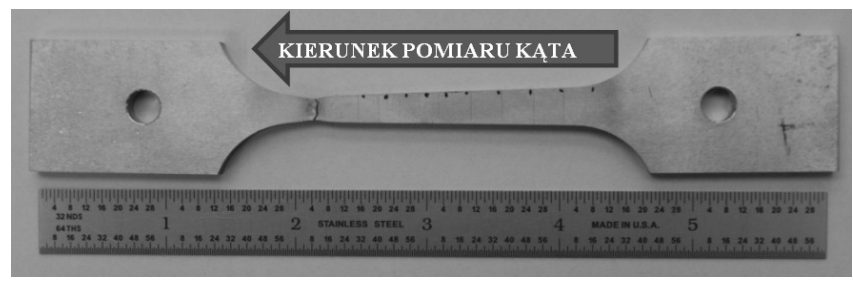

Rys. 5. Złom próbki, na którym dokonano pomiarów kąta fazowego od sygnału "lift off"

Fig. 5. Scrap samples which phase angle the signal "lift off" was measured

Zaobserwowano ogólną zależność pomiędzy wartościami kąta fazowego impedancji zespolonej prądów wirowych w stopie niklu a stanem jego deformacji i określonym na tej podstawie - parametrem uszkodzenia. Wynik ten, uzyskany dla obu częstotliwości pokazano na rysunku 6, wraz z przykładowym obrazem krzywych impedancji uzyskanych w kolejnych punktach na całej długości próbki. Skrajna trajektoria odpowiada pomiarowi w części chwytowej próbki, gdzie założono zerowy stopień uszkodzenia, a krzywa ma charakter referencyjny. Pozostałe krzywe odpowiadają kolejnym obszarom próbki, zgodnie z kierunkiem na rysunku 6

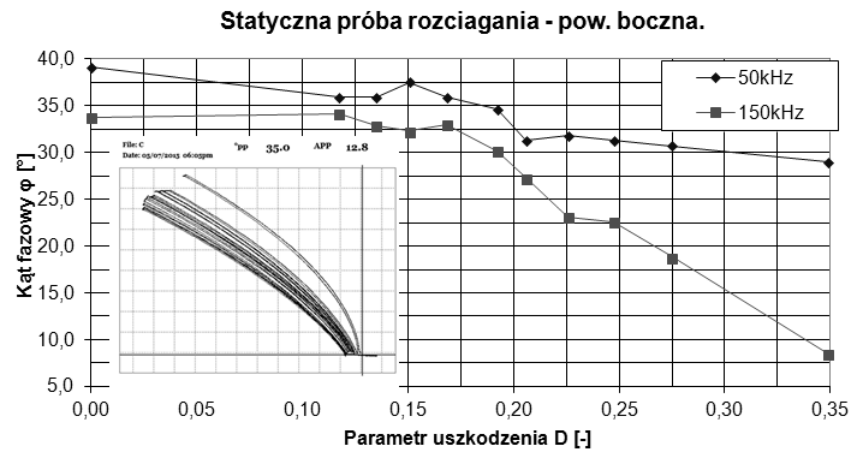

Rys. 6. Przebiegi zmian wartości kata fazowego w funkcji parametru uszkodzenia

Fig. 6. Changes of the phase angle as a function of the damage parameter

Uzyskany wynik wskazuje na niemal liniową zależność mierzonego kąta fazowego impedancji od parametru uszkodzenia, dla obu częstotliwości prądu wzbudzającego. Jednak od wartości parametru uszkodzenia ok. 0,2 widać dużo większą dynamikę zmian kąta fazowego dla częstotliwości $150 \mathrm{kHz}$. Ponieważ częstotliwość prądu wzbudzającego wtórne prądy wirowe wpływa na głębokość ich wnikania w materiał, można uznać, że mniejsza głębokość penetracji, daje większy efekt zmian mierzonego kąta w funkcji stopnia uszkodzenia. Dla częstotliwości $150 \mathrm{kHz}$ wnikanie prądów ogranicza się do głębokości niespełna $1,5 \mathrm{~mm}$, zaś dla $50 \mathrm{kHz}$ ponad $2,5 \mathrm{~mm}$. Rejestracja zmian z większej grubości materiału powoduje niejako tłumienie efektu uszkodzenia bowiem dominuje ono na powierzchni. Można, zatem uznać, że proces uszkodzenia materiału próbki pod wpływem statycznego obciążenia inicjowany jest na powierzchni próbki i w tym też obszarze się rozwija.

\section{Wnioski}

Zaproponowana metodyka oceny stopnia uszkodzenia w oparciu o lokalny pomiar odkształcenia skorelowany z pomiarami parametru prądowirowego pozwala nie tylko na skuteczną analizę ilościową, ale także na lokalizację efektu kumulacji uszkodzenia, związanego z lokalizacją odkształcenia. Ponadto powierzchniowy charakter badań z wykorzystaniem prądów wirowych pozwolił na potwierdzenie powierzchniowego charakteru rozwoju uszkodzenia w warunkach mechanicznych obciążeń statycznych.

W przypadku przygotowania zestawu próbek odniesienia z określonego materiału i o zdefiniowanym stopniu uszkodzenia, (co jest zaplanowane w dalszych pracach zespołu autorskiego) możliwe jest opracowanie procedury nieniszczącej oceny stopnia uszkodzenia dedykowanej dla konkretnych elementów konstrukcji i instalacji przemysłowych. Pozwoliłaby ona na monitorowanie rozwoju degradacji w warunkach pracy.

\section{Literatura}

[1] Socha G., Krysztofik J.: Badania uszkodzeń stopu Inconel 718 stosowanego w lotnictwie, XXI Seminarium Szkoleniowe "Nieniszczące Badania Materiałów", Zakopane 2015.

[2] Szlagowska-Spychalska J., Kukla D., Dragan K.: Metoda prądów wirowych do oceny konstrukcji lotniczych z uwzględnieniem metod modelowania sygnałów elektromagnetycznych, Oficyna Wydawnicza Politechniki Warszawskiej, Warszawa, 2014.

[3] Socha G., Madejski B., Krysztofik J., Czarnewicz S.: Sposób badania uszkodzenia struktury materiału wywołanego deformacją trwałą próbki poddanej rozciąganiu i próbka do badania uszkodzenia struktury materiału, 2014, UPRP nr P-409294.
[4] Johnson G. R.: Materials Characterization for computations invoIving severe dynamic loading, Proc. Army Symp. Of Solid Mechanics, pp. 62-67, Cape Cod, Mass., 1980.

[5] Socha G.: Nowa metoda wczesnego wykrywania i monitorowania kumulacji uszkodzeń stali konstrukcyjnych, Prace Instytutu Lotnictwa, 189, 2007 